\title{
Nano fluid- An alternative fluid in Pulsating Heat Pipe/Oscillating Heat Pipe
}

\author{
BhawnaVerma $^{1}$, V.L.Yadav ${ }^{2}$, K.K.Srivastava ${ }^{3}$ \\ 1, 2, 3 (Department of Chemical Engg. I.I.T.B.H.U.Varanasi-221005 U.P.India)
}

\begin{abstract}
The present article reviews the various features of nano fluid as an alternative fluid in pulsating heat pipe(PHP) which has high thermal performance required in cooling technologies of electronics engineering along with the factors affecting the performance of PHP with nano fluids. The need of nano fluid in heat pipes is discussed. Effect of nanofluid on heat transport capability of PHP/OHP is covered. Reasons for improved heat transfer with nano fluids are discussed. Effects of nano fluids on various parameters like Rwall, Ri-v,Revap\&Rcond, flow pattern, startup of a PHP \& thermal resistance are included. Results of experiment performed to study the effect of nano fluid concentration on thermal resistance of PHP have also been discussed. It is concluded that nano fluids are potential fluids to be used as working fluid in PHP.
\end{abstract}

Keywords: pulsating heat pipeloscillating heat pipe, nanofluids, working fluids, heat transfer enhancement, thermal resistance, startup of PHP.

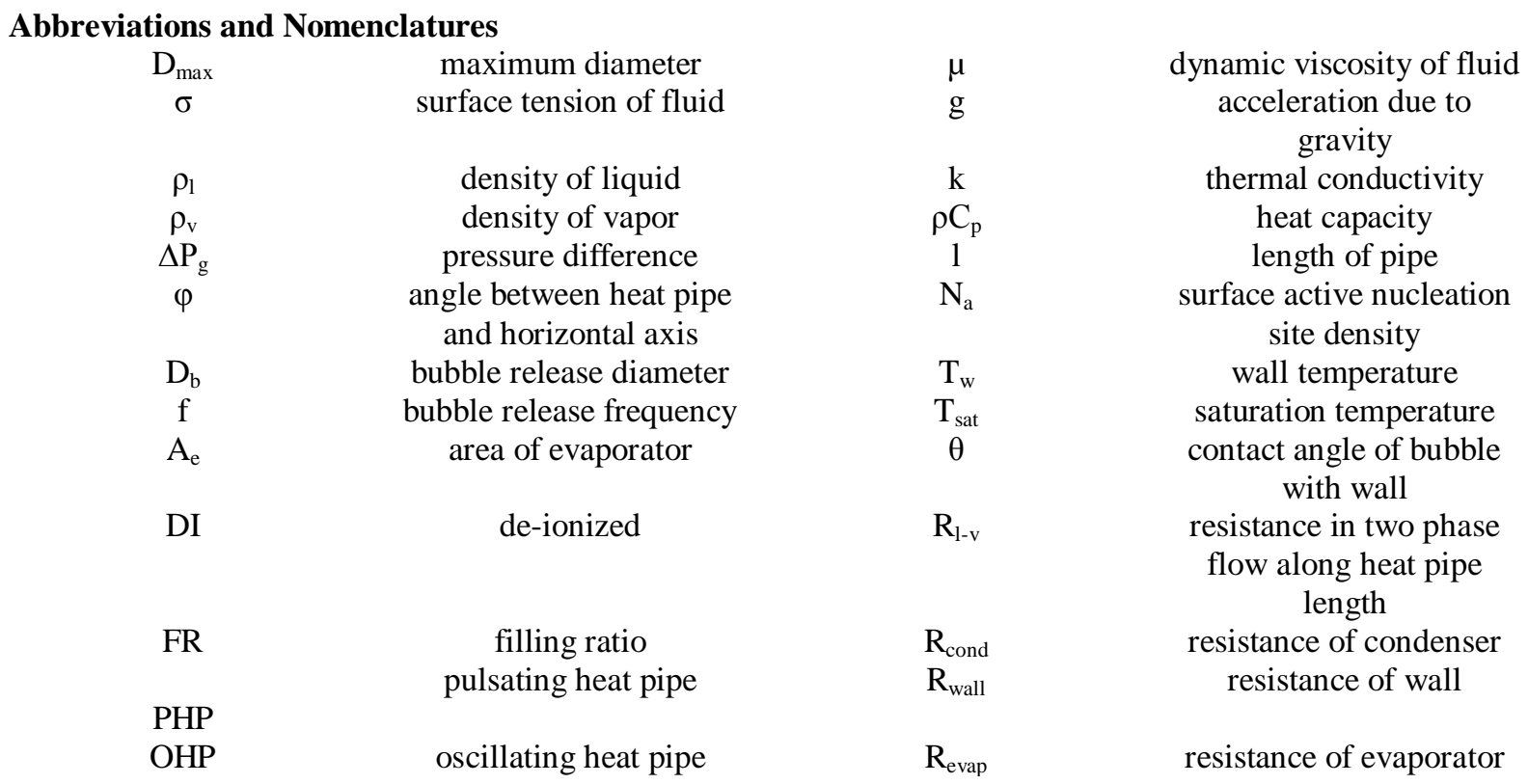

\section{Introduction}

Miniaturization is in vogue and this euphoria has especially gripped the electronics and allied industry. The insatiable urge for going nano does not come with associated inter-disciplinary technological problems. Although this increased power-decreased size scenario has been prevalent for many decades, in recent years, thermal management has become the major feasibility bottleneck for microelectronics. High heat density has complemented to the problem of high power dissipation. Although a number of cooling technologies using miniaturized devices, large devices (e.g. transportation trucks) and new energy technology (e.g. fuel cells) are under development, they all require more efficient cooling systems with greater cooling capabilities. Particularly systems using Nano fluids may show great promise because of their manifold improved physical and chemical properties. The requirement of enhanced cooling technology which is a need of the present day technology may be met by introducing new designs for cooling devices such as micro channels and miniature Cryo-devices and enhancing the heat transfer.

Two phase traditional heat pipes prove to be a bit effective for the removal of large quantities of heat, but, as the total power increases (higher than $300 \mathrm{~W} / \mathrm{cm}^{2}[1]$ ), although the pressure drop occurring in wick structures or flow paths for liquid/vapor flow in a heat pipe significantly increases due to the frictional shear stresses, which directly limits the heat transfer capability in a traditional heat pipe. Compared with the traditional heat pipe, the PHP, proposed and patented by Akachi in early 1990's [2], is a new member of the 
wickless heat pipes. It has excellent features, such as high thermal performance, rapid response to high heat load, simple design and low cost [3]. The PHP/OHP has a number of unique features as follows:

(i) It is an "active" cooling device that converts heat from the heat generating area into the kinetic energy of liquid plugs and vapor bubbles to initiate and sustain the oscillating motion.

(ii) Since both phases flow in the same direction, the liquid flow does not interfere with the vapor flow.

(iii) The thermally-driven oscillating flow inside the capillary tube effectively produces some free surfaces that significantly enhance evaporating and condensing heat transfer.

(iv) The oscillating motion in the capillary tube significantly enhances the forced convection in addition to the phase-change heat transfer.

(v) As the input power increases, the heat transport capability of a PHP dramatically increases [4].

Such heat pipes have already shown high promise for terrestrial and space applications.

The working fluids used as heat transfer fluids exhibit poor thermal conductivity which limit the heat transfer properties. Due to manifold improved thermal, mechanical, electrical and optical properties of nanometer - sized particles, nano fluids may be used in PHP/OHP systems. Das et al [5] in their review article showed great promise regarding heat transfer using nano fluids in cooling technologies. Use of Nano fluids as working fluids in PHP has attracted researchers all over the world and a number of recent high quality articles have been published on such work [4,6-12]. The present article reports a brief review of the contributions made by different workers in this direction along with its future. A brief account of working principle of PHP is also presented in the beginning. It should be noted that no review article has been published on the recent contributions on the nano fluidic effects on PHP/OHP.

\section{Working Principle Of Php/Ohp}

The PHP is a special type of heat pipe where the driving force is the slug/plug motion of the working fluid in the tube, generated by the evaporation. PHPs consist of a meandering tube bent to form several parallel channels (fig 1) [13]. It can be configured as an open loop, closed loop and closed loop with check valves (Fig 2). In the first one, one end of the PHP is pinched-off and welded; while the other end presents a service valve for vacuum and charge (this valve can be later removed). The Closed loop PHP is an endless tube as both ends are welded together, while closed loop with check valves incorporates one or more direction control one-way check valves in the loop so that the working fluid can circulate in specified direction only. Each PHP configuration presents particular operation modes, which are mainly guided by the chaotic slug/plug motion of the working fluid.

Karimi and Culham [14] used Akachi and Pohsek s' [2] theoretical maximum tolerable inner diameter of PHP tube as

$$
D_{\text {max }}=2 \sqrt{\frac{\sigma}{\left(\rho_{\text {liq }}-\rho_{\text {vap }}\right) g}}
$$

same as used by Khandekar[15] ( but based on balance of capillary and gravity forces).

The performance of a PHP depends upon many factors like the geometrical parameters of flow channel, the working fluid, the filling ratio , number of turns, PHP configuration and the inclination angle [16].Selection of a suitable working fluid for heat transfer application depends on many considerations viz. the operating temperature range, the compatibility with the materials, the thermophysical properties of the fluid like good thermal stability, high latent heat, high thermal conductivity, low liquid and vapor viscosities, high surface tension and acceptable freezing point [17].

It is obvious from a survey of thermal properties of working fluids used today as heat transfer fluids exhibit extremely poor thermal conductivity (with the exception of liquid metals, which cannot be used at most of the pertinent useful temperature ranges)[5]. For example, water is roughly three orders of magnitude poorer in heat conduction than copper - as is the case with engine coolants, lubricants, and organic coolants. It goes without saying that all of the efforts to increase heat transfer by creating turbulence, increasing area, etc., will be limited by the inherent restriction of the thermal conductivity of the fluid. Thus, it is logical that efforts should be made to increase the thermal conduction behavior of cooling fluids.

Using the suspension of solids is an option that came to mind more than a century ago. Modern materials technology provided the opportunity to produce nanometer-sized particles which are quite different from the parent material in mechanical, thermal, electrical, and optical properties. Das et.al. [5] in their review of heat transfer in nano fluids concluded great promise for use of nanofluids in cooling technologies. Thus, nanofluid technology coupled with new heat-transfer-related studies on microchannel flow [18] has provided a new option as working fluid in PHP of revisiting suspensions of nanoparticles. 


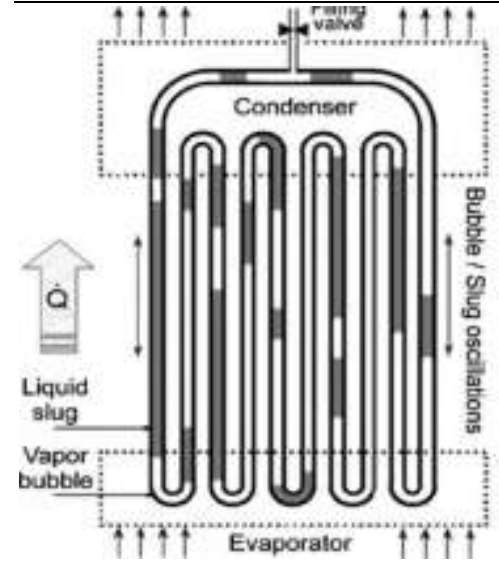

Fig 1 Schematic of a Pulsating Heat Pipe[3] .

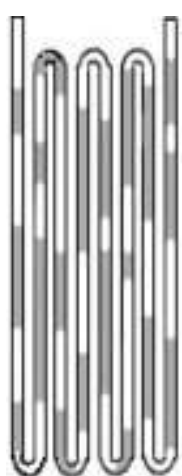

(a)

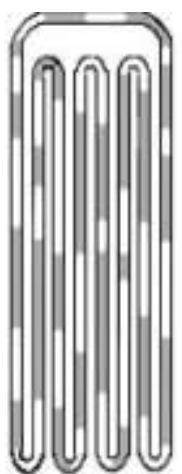

(b)

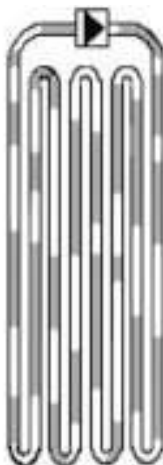

(c)

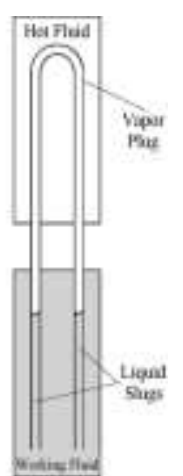

(d)

Fig 2 Different PHPs: (a) closed-end, (b) closed-loop, (c) closed-loop with check valve, and (d) PHP with open ends[16]

\section{Nanofluid As The Working Fluid For Php/Ohp}

TABLE 1 summarizes the work done by the various researchers using nanofluid as working fluid in PHP/OHP. The nanoparticles exhibit large surface area, less particle momentum and high mobility. The thermal conductivity of nanoparticles also significantly increases with a rise in temperature and increase in volume fractions[19,6]. Particles finer than $20 \mathrm{~nm}$ carry $20 \%$ of their atoms on their surface, making them instantaneously available for thermal interaction. Another advantage is the mobility of the particles, attributable to the tiny size, which may bring about micro-convection of fluid and hence increased heat transfer $[7,29]$. The micro-convection and increased heat transfer may also increase dispersion of heat in the fluid at a faster rate. Apart from this, the thermo-physical properties of the base fluid also gets affected by the addition of nanoparticles. It is already found that the thermal conductivity of nanofluids increases significantly with a rise in temperature [30], which may be attributed to the above reasons. The presence of nanoparticles in water increases the thermal conductivity $(\mathrm{k})$ of the working fluid. The nanoparticles can absorb liquid molecules, and thus result in the formation of molecular nanolayer on the surface of nanoparticles [31,32], which has a thermal conductivity higher than that of the bulk liquid and can intensify the heat transfer in the interior of the fluid; the addition of nanoparticles to water changes the heat capacity $(\rho \mathrm{Cp})$ of the working fluid. For the nanofluids having a higher heat capacity than the base water, more heat will be transferred by the fluid if the flow rate remains unchanged based on the convection heat transfer theory; the dynamic viscosity $(\mu)$ of the fluid is also varied due to the addition of nanoparticles. For a nanofluid having a higher viscosity than base water, the increased viscosity means lower flow rate and thus less heat can be transferred by the fluid in the PHP. But if the concentration of the nanoparticle is less, the effect of viscosity on heat transfer can be neglected. Nanoparticles are very small, and the momentum they can impart to a solid wall is much smaller. This reduced momentum reduces the chances of erosion of components, such as heat exchangers, pipelines and pumps [17].

It is projected that the next generation of computer chips will produce localized heat flux over 10 $\mathrm{MW} / \mathrm{m}^{2}$, with the local power exceeding $300 \mathrm{~W}$. No existing low cost cooling device can effectively manage the heat produced at this level. Combining thin film evaporation, nanofluid and oscillating motion, it can be said that PHP appears to be the most favorable option for removing heat fluxes over $10 \mathrm{MW} / \mathrm{m}^{2}$ [8].

\section{Nanofluids As Working Fluid In Other Heat Pipes}

Tsai et al [33 ] first studied the effect of nano fluids on simple heat pipe and found that the resistance of the heat pipe decreased tremendously when the base fluid was replaced by nanofluid. The circular meshed heat pipe had a length $170 \mathrm{~mm}$ and an outer diameter of $6 \mathrm{~mm}$. The heat pipe thermal resistance ranged from 0.17 to $0.215^{\circ} \mathrm{C} / \mathrm{W}$. They selected gold nano particles of different sizes. As compared to the resistance obtained with DI water, there was a reduction of $33 \%$ to $56 \%$ in the evaporator, while the reduction in case of condenser was only $7 \%$ to $20 \%$. Tsai et al attributed low thermal resistance in heat pipe due to presence of nanoparticles to the probable reduction in bubble release diameter by way of impact of nanoparticles.

There after variety of nano particles and base fluid in heat pipe have been reported such as silver [9,34], $\mathrm{Cu}[35]$ and $\mathrm{CuO}[10,35,36], \mathrm{Al}_{2} \mathrm{O}_{3}$ [36,37], diamond[1,8], titanium[36,38,39], nickel oxide[40], silica[35]. $\mathrm{A}$ reduction in thermal resistances[34-37], reduction in liquid velocity[36](velocity is inversely proportional to density and viscosity) and reduction in startup time[10] has been observed which improved the thermal performance of the heat pipe. Other factors which improved the thermal performance were drop in temperature gradient along the heat pipe[36,37] and an enhanced overall heat transfer coefficient[10] ( the metallic nanoparticle e.g. $\mathrm{Cu}$ will have better heat transfer enhancement than its oxide i.e. $\mathrm{CuO}$, as $\mathrm{Cu}$ is smaller in size). 
The $\mathrm{SiO}_{2}$ nanofluid deteriorates contrarily [35] the thermal performance of the heat pipe, the reason being its structure, discussed later in the paper.

\section{Effect Of Nanofluid On Different Parameters Of Php/Ohp}

In their model Ma et al. [1] considered the thermal energy due to temperature difference between the evaporator and condenser as the driving force for oscillatory motion. In their experimental investigation [20] temperature difference between evaporator and condenser was reported to decrease significantly from 40.9 to $24.3^{0} \mathrm{C}$ when diamond nanoparticles were employed. The strong oscillatory motion made the nanoparticles to remain suspended and thus the nanofluid was a stable working fluid.

\subsection{Effect of nanofluid on heat transport capability of PHP}

As the heat input increases, the oscillating motion becomes stronger and stronger. The effect of operating temperature on the heat transport capability was also checked [20].The operating temperature also significantly affected the heat transport capability in the PHP and when the operating temperature was increased, the heat transport capability increased(Fig 3). However, at higher heat load and higher operating temperature no significant change was observed. The investigated PHP charged with nanofluids can reach a thermal resistance of $0.03^{\circ} \mathrm{C} / \mathrm{W}$ at a power input of $336 \mathrm{~W}$.

Reihl in 2006 [21] studied the performance of a CuOnanofluid (5\%) in water with a PHP with 6 turns. Considerable drop in temperature of the evaporator, condenser and adiabatic section was observed. In 2007 Park and Ma [22] checked the performance of the PHP using $1.0 \mathrm{vol} \% \mathrm{CuNi}$ nanoparticles which were fabricated with $20 \mathrm{~kW}$ RF plasma with a high frequency of $13.56 \mathrm{MHz}$. The results show that the filling ratio influences the effect of the nanofluid on the heat transport capability. An optimum filling ratio was 50\% was obtained. Chiang et.al. [23] used diamond nano fluid with $0.5 \mathrm{wt} \%$ concentration and found that optimum filling ratio depends on the structure of PHP; with 36 port PHP, the optimum filling ratio was 50\% while with 26 port PHP, it was $20 \%$.

Lin et al. [24] compared the performance of 100ppm and 450ppm silver nanofluid(size $20 \mathrm{~nm}$ ) with the base fluid, DI water and found the optimum filling ratio as 60\%. In a PHP, considerable high filling ratio hinders the pulsation of the bubble and the efficiency of heat transfer is not favourable enough. The low filled ratio gets pulsation of the bubble easily, but it is extremely easy to dry out. Hence, the optimum filling ratio comes around 50-60\%, so that the effect of pulsation and bubble production gets balanced. In comparison to 450 ppm, 100ppm Ag nanofluid gave better heat transfer result. When the filled ratio was $60 \%$ and the heating power $85 \mathrm{~W}$, the average temperature difference of evaporator and condenser compared with the pure water was less than $7.79^{\circ} \mathrm{C}$, and the thermal resistance was also less than $0.092{ }^{\circ} \mathrm{C} / \mathrm{W}$.

Wang et.al. [41] compared the performance of base fluid water $\mathrm{Al}_{2} \mathrm{O}_{3}$ nanofluid on a PHP made of copper with a filling ratio 50\%. The heat transport capability of PHP with $\mathrm{Al}_{2} \mathrm{O}_{3}$ was better than pure water above $40 \mathrm{~W}$ regardless of horizontal or vertical mode of operation. The optimum concentration in vertical modewas $0.5 \mathrm{wt} \%$ and $1 \%$ in horizontal mode. Wannapakhe et al.[25] also obtained same result for optimum concentration of $\mathrm{Ag}$ nano fluid $0.5 \% \mathrm{w} / \mathrm{v}$. they also studied the effect of evaporator length and inclination angle on closed loop pulsating heat pipe with check valves(CLOHP/CV). The inclination angle of the CLOHP/CV has an effect on the heat transfer rate because of a pressure difference $(\Delta \mathrm{Pg})$ brought about by the hydrostatic head of liquid being positive, negative, or zero. This depends on the fluid density, acceleration from gravity force, tube length, and inclination angle of the CLOHP/CV to the horizontal axis. The pressure difference may be determined from following Eq. [42]:

$\Delta P_{g}=\rho_{l} g l \operatorname{Sin} \varphi$

where $\rho_{l}$ is the liquid density $\left(\mathrm{kg} / \mathrm{m}^{3}\right), g$ is the acceleration due to gravity $\left(9.81 \mathrm{~m} / \mathrm{s}^{2}\right), l$ is the heat pipe length $(\mathrm{m})$, and $\varphi$ is the angle between the heat pipe and the horizontal axis $(\varphi$ is positive when the condenser is lower than the evaporator).

The heat transfer rate was maximum for an inclination angle of $90^{\circ}$, which was $8.88,4.13$ and $7.69 \mathrm{~kW} / \mathrm{m}^{2}$ respectively for evaporator length $50 \mathrm{~mm}, 100 \mathrm{~mm}$ and $150 \mathrm{~mm}$, and nanoparticle concentration $0.5 \% \mathrm{w} / \mathrm{v}$. The best heat flux was $13.19 \mathrm{~kW} / \mathrm{m}^{2}$ at an aspect ratio (Le/D) of 25 , an operating temperature of $60^{\circ} \mathrm{C}$, and a silver nanofluid concentration of $0.5 \%$ w/v (Fig 4) [25].

Qu et.al. [11] also studied the effect of concentration of $\mathrm{Al}_{2} \mathrm{O}_{3}$ nanoparticles $(56 \mathrm{~nm})$ solution in water on the thermal resistance of PHP. The thermal resistance decreased from $0 \%$ to $0.9 \%$ but it increased for $1.2 \%$ concentration of nanofluid. The maximum decrease was about $0.14{ }^{\circ} \mathrm{C} / \mathrm{W}(32.5 \%)$ as compared to that of water for $70 \%$ filling ratio. In the SEM studies it was shown that settlement of nanoparticles occurred both at the evaporator and the condenser, though the agglomeration was more at the evaporator. Thus, the resistance of the condenser was nearly the same for nanofluids and pure water. The change in resistance mainly occurred at the evaporator. 
Studies were also conducted on similar set up to compare the performance of silica and alumina nanofluids with the base fluid water [26]. The evaporator wall temperature and the overall thermal resistance both decreased as compared to pure water but in case of silica nanoparticles, both the evaporator temperature and the total thermal resistance increased (fig 5). This effect became more prominent after the concentration of silica nanoparticle increased from $0.1 \%$ to $0.6 \%$.

Reihl [27] conducted the studies on open loop pulsating heat pipe using $\mathrm{Cu}$ nano particles at a concentration of $5 \mathrm{wt} \%$ and found a considerable improvement in the performance of the device. The mean evaporation section temperature which stabilized at $118^{\circ} \mathrm{C}$ for pure water was $90^{\circ} \mathrm{C}$ for nanofluid at $50 \mathrm{~W}$. There was also a decrease in the critical diameter of the bubbles by the use of nanofluid. For a saturation temperature of $20^{\circ} \mathrm{C}$, the critical diameter for water was $5.45 \times 10^{-3} \mathrm{~m}$ while that for water-copper nanofluid (addition of $5 \%$ by mass) wa2s $5.33 \times 10^{-3} \mathrm{~m}$. This directly contributed to increase the vapor bubble formation and thus the pulsations were more intense. It was also observed that the temperature differences between the evaporator and the adiabatic sections were smaller for high heat loads when nano fluid was used. In this case, the film evaporation effect is more predominant than the nucleate boiling, which directly affects the pulsating flow.

\subsubsection{Reasons for improved heat transfer with nanofluids}

The heat transfer capacity of the nanofluids showed better results than the base fluid [21, 24, 25, 41]. Reihl[21] reasoned that the improvement in thermal behavior of the device was because of the fact that the amount of fluid is always constant in case of nanoparticles. The increase in heat transfer with nanofluid is also because of the large surface area[ 25], which increases the heat conduction between the base fluid and the particles; the small size of the particles and their speed of Brownian motion, which makes the micro-convection heat movement quick[41] (which was in contradiction to the studies made by Eapen et.al. [43] and the increased thermal conductivity $[25,41]$ ). Also the size of nano particle powder being close to phonon, thus the nanopowder particle penetrates the based fluid to form a short circuit and reduces the thermal resistance [41]. The thermal resistance of PHP with nanofluid as the working fluid greatly decreased [41] in comparison to the base fluid; but it increased in case of silica nanoparticles [26].The thermal resistance of a PHP depends on the filling ratio, lowering of filling ratio led to a smaller resistance. The total resistance can be calculated as [25]:

$R=2 R_{\text {wall }}+R_{l-v}+R_{\text {evap }}+R_{\text {cond }}$

Where $R_{\text {wall, }} R_{1-v}, R_{\text {evap }}, R_{\text {cond }}$ are conductive resistance in the pipe wall, the thermal resistance in the two phase flow along the heat pipe length and the thermal resistance at the evaporator and that at the condenser respectively.

\subsubsection{Effect on $\boldsymbol{R}_{\text {wall }}$}

Generally $R_{\text {wall }}$ is small and independent of the working fluid used.

\subsubsection{Effect on $R_{l-v}$}

Mainly theheat transfer in this section occurs due to convection, and thus depends upon the thermophysical properties of the working fluid viz. thermal conductivity, heat capacity and dynamic viscosity of the fluid.The presence of nanoparticles in water increases the thermal conductivity $(\mathrm{k})$ of the working fluid. The nanoparticles can absorb liquid molecules, and cause the formation of molecular nanolayer on the surface of nanoparticles [44, 45], which has a thermal conductivity higher than that of the bulk liquid and can intensify the heat transfer in the interior of the fluid; the addition of nanoparticles to base fluid changes the heat capacity $(\rho \mathrm{Cp})$ of the base fluid; the dynamic viscosity $(\mu)$ of the fluid is also varied due to the addition of nanoparticles. For a nanofluid having a higher viscosity than base water, the increased viscosity means lower flow rate and thus less heat can be transferred by the fluid in the OHP; in addition to the above thermophysical parameters, nanoparticles migration motion and its induced microconvection in the aqueous suspension were also assumed to enhance the convective heat transfer of the working fluid.However, the effect of these factors will be small as the concentration of the nanofluid used by the various researchers is very low. [26].

\subsubsection{Effect on $\boldsymbol{R}_{\text {evap }}$ and $\boldsymbol{R}_{\text {cond }}$}

The thermal resistances $R_{\text {evap }}$ and $R_{\text {cond }}$ are greatly influencedby the inner surface conditions. The thermal resistance due to nucleate boiling at the evaporator is given by [46]:

$R_{\text {evap }}=\frac{1}{h A_{\theta}}=\frac{1}{2 N_{a} D_{b}^{g} \sqrt{f}, \sqrt{\pi K \rho C_{\mathrm{p}} A_{g}}}$

where, $\mathrm{Na}, \mathrm{Db}, \mathrm{f}, \mathrm{k}, \rho, \mathrm{cp}$ are the surface active nucleation site density, bubble release diameter, bubble release frequency, liquid thermal conductivity, density and specific heat, respectively. Considering that the variation of product (kpcp) due to the addition of nanoparticles be less than $1.1 \%$, and the increase of surface heat transfer area at the evaporator $(\mathrm{Ae})$ due to the deposition of nanoparticles be less than $2.1 \%$, then the above equation simplifies [26] to 


\section{$R_{\text {evap }} \propto \frac{1}{N_{a} D_{b \sqrt{f}}^{2}}$}

Wang and Dhir[47]correlated their experimental data to give the expression of surface active nucleation site density as follows,

$N_{a} \propto N_{c}(1-\cos \theta)\left(T_{w}-T_{w a t}\right)^{6}$

where, $\mathrm{Nc}$ is the micro-cavity density on the surface, $\theta$ is the surface contact angle, and $\left(\mathrm{T}_{\mathrm{w}}-\mathrm{T}_{\text {sat }}\right)$ is the wall superheat. It is clear from Eq.( 6) that decreasing contact angle $\theta$ (or increasing surface wettability) tends to decrease the active nucleation site density and deteriorate the boiling heat transfer at the evaporator. Fig 6 shows that the surface contact angle at the evaporator decreased from $65^{\circ}$ for the clean surface to $29^{0}$ and $54^{0}$ for the silica and alumina nanoparticle-deposited surfaces, respectively. The surface contact angle at the evaporator decreased after the deposition of nanoparticles, thus thermal performance of the $\mathrm{SiO}_{2}$ nanofluids-charged PHP deteriorated. For the silica nanoparticle the average size of the agglomerates was about 2-3 $\mu$, which was of the same magnitude as the clean surface cavities. Thus the micro cavity density decreased, as the silica nano particles crammed into the surface cavities and thus deteriorated the nucleate boiling heat transfer. [26].

The deposition of nanoparticles on the condenser surface may also affect the resistance of condenser, $\mathrm{R}_{\text {cond. }}$ As in case of silica, the deposition was appreciable, hence the thermal resistance increased [26] while the deposition of alumina nanoparticle was negligible, hence it did not affect $\mathrm{R}_{\text {cond. }}$. Also the size of alumina nanoparticle agglomerates deposited on the boiling surface was several ten to hundred nano-meters (measured by the AFM) [26], which were one to two orders of magnitude smaller than the cavities of clean surface. As a result, when the smaller alumina nanoparticles deposited on the clean surface, they created more new active nucleation sites by splitting a single nucleation site into multiple ones (i.e., $\mathrm{Na}$ is increased), and thus enhanced the boiling heat transfer.

\subsection{Effect of nanofluid on flow pattern}

There are four types of flow pattern in a PHP: slug flow, annular flow, bubble flow and disperse flow. The annular flow occurs at low temperature, low thermal conductivity, fluid, and high aspect ratio (Le/D). The heat flux of the slug flow is better [25] than the annular flow, the heat flux of the bubble flow is higher than the slug and annular flow, and the best heat flux is dispersed flow. It occurs at a high temperature and a low aspect ratio. With the same fluid, the flow pattern at the inner tube changes from annular flow to slug, bubble, or dispersed flow when the operating temperature is increased.

Bhuwakietkumjohn and Rittidech[12] compared the flow behavior of working silver nanoparticles in ethanol with the base fluid. When the heat source temperature was low $\left(85^{\circ} \mathrm{C}\right)$, annular flow with very few nucleation sites appeared and slug flow with more nucleation sites was observed in the lower part of the evaporator. Slug flow and annular flow dominated the lower and middle parts of the evaporator. As the temperature was increased to $105^{\circ} \mathrm{C}$, slug flow and bubble flow with more nucleation sites were observed in the lower part of evaporator. Bubble flow and slug flow dominated the middle and upper part of the evaporator. On further increasing the temperature to $125^{\circ} \mathrm{C}$ dispersed bubble flow with very few nucleation sites appeared in the lower part of the evaporator. The flow behavior was the same for both the fluids. But considerable increase in the heat could be observed. For evaporator length of 50mm, the flux increased 50, 32 and 55\% for 85, 105 and $125^{\circ} \mathrm{C}$ respectively. The vapor slug length reduced by 1.5 times to 1.8 times while the velocity of the vapor plug increased by 2.3 times to 1.87 times by the use of nanofluid, as the temperature increased from $85^{\circ} \mathrm{C}$ to $125^{\circ} \mathrm{C}$. When the evaporator length was increased to $100 \mathrm{~mm}$, the flux increased by 3.44 times at $85^{\circ} \mathrm{C}$ while the increase was 2.8 times for 105 and $125^{\circ} \mathrm{C}$ respectively. As vapor slug length increased to $0.041 \mathrm{~m}$ which was $0.0034 \mathrm{~m}$ at $85^{\circ} \mathrm{C}$, but it decreased from 0.0995 to 0.036 and from 0.907 to $0.028 \mathrm{~m}$ at 105 and $125^{\circ} \mathrm{C}$. Similarly the slug velocity decreased from $0.1873 \mathrm{~m} / \mathrm{s}$ to $0.0434 \mathrm{~m} / \mathrm{s}$ at $85^{\circ} \mathrm{C}$, while it increased from $0.0068 \mathrm{~m} / \mathrm{s}$ to $0.0566 \mathrm{~m} / \mathrm{s}$ and from 0.0091 to $0.0625 \mathrm{~m} / \mathrm{s}$ at 105 and $125^{\circ} \mathrm{C}$.

\subsection{Effect of nanoparticle size on startup of a PHP \& thermal resistance of PHP/OHP}

For both PHPs either charged with pure water or nanofluid, there exists a startup heat input. When the heat input is less than this required startup, no oscillating motions are observed and the temperature difference between the evaporator and condenser increases linearly as the power input is increased. When the temperature is higher than the point when the temperature fluctuations are observed, temperature oscillations start and the temperature acquires a steady value. This indicates that the oscillating motion has started and PHP starts to function. This point is called the startup temperature. The startup condition is very important for the stable oscillating motion occurring in a PHP. The PHP startup depends on many factors such as the wall temperature variation, heat flux level, physical properties of working fluid, heating and cooling modes, transient heat transfer process, initial temperature, and so on [48].

Ma et.al.[20]studied the effect of nanoparticles on startup of the PHP and found that the heat resistance was same as that obtained with base fluid as the working fluid, before the heat input reached the startup i.e. when there was no oscillations. When the evaporator is at the bottom, the nanoparticles stay in the evaporator 
section. Once the oscillating motions starts and the nanoparticles are well mixed, the thermal resistance reduces significantly.

Ji etal. [4] investigated the effect of four different particle sizes of $\mathrm{Al}_{2} \mathrm{O}_{3} \mathrm{viz} .20 \mu \mathrm{m}, 2.2 \mu \mathrm{m}, 80 \mathrm{~nm}$, and $50 \mathrm{~nm}$ and the base fluid water on the startup temperature and thermal resistance of a PHP/OHP. When the particle size became smaller, the startup temperature decreased. For the largest particles of $20 \mu \mathrm{m}$ tested herein, the startup temperature was $48.5{ }^{\circ} \mathrm{C}$, while for the $50 \mathrm{~nm}$ particles the startup temperature was $40.6{ }^{\circ} \mathrm{C}$. As the particle size reduced from $20 \mu \mathrm{m}$ to $80 \mathrm{~nm}$, the heat transport capability increased or the thermal resistance decreased. But if the particle size further decreased less than $50 \mathrm{~nm}$, the thermal resistance could not be further reduced, i.e., there exists an optimal particle size for the maximum heat transport capability. Among four particles of $20 \mu \mathrm{m}, 2.2 \mu \mathrm{m}, 80 \mathrm{~nm}$, and $50 \mathrm{~nm}$ tested herein, $80 \mathrm{~nm}$ particles resulted in the best heat transport capability for the OHP investigated herein, the thermal resistance was $0.113{ }^{\circ} \mathrm{C} / \mathrm{W}$ at $25{ }^{\circ} \mathrm{C}$ and a power input of $200 \mathrm{~W}$.

By using $\mathrm{Al}_{2} \mathrm{O}_{3}$ nanofluid of particle size $45 \mathrm{~nm}$ in de-ionised water base with filling ratio $50 \%$ in a PHP using copper tubes of 6 turns and inner diameter $1.4 \mathrm{~mm}$, Bhawna et al (49) investigated the effect of $\mathrm{Al}_{2} \mathrm{O}_{3}$ nano particle concentration on the thermal resistance of PHP at different orientations. Fig. 7 shows the experimental results at vertical orientation. It was found that as the concentration increased from $0.25 \%$ to $1 \%$ the thermal resistance reduced in comparison to DI water, but as the concentration increased from $1.5 \%$ to $5.0 \%$, the thermal resistance was more than that of water. Thus the optimum concentration of $\mathrm{Al}_{2} \mathrm{O}_{3}$ was $1.0 \%$.

\subsection{Effect of nanoparticle shape on thermal resistance of PHP/OHP}

Ji et al. in 2011[28] tested the effect of shape of alumina nanoparticle. The nanoparticles of boehmite alumina with different shapes, platelet(P1), blade(P2), cylinder(P3) and brick(P4) were studied for varying concentration, $0.3,1,3$ and 5 vol\%. A binary mixture of ethylene glycol and DI water (50/50 by volume) was used as the base fluid. The optimum concentration varied with the shape of the particles. For the PHPs charged with platelet, blade and brick,the optimum volume fraction was about $0.3 \%$ while for the PHP charged with cylinder; the optimum fraction was $1 \%$. At operating temperature $20{ }^{\circ} \mathrm{C}$ for input power less than $100 \mathrm{~W}$, heat transfer enhancement from the highest to lowest is: P3> P2 > P1 > P4 and for input power more than $125 \mathrm{~W}$ sequence of heat transfer enhancement from the highest to lowest becomes: P4 > P3 > P1> P2 for the optimum concentration. But overall cylinder shape gave the best performance.

\subsection{Effect of nanofluid concentration on PHP:}

Bhawna etal.[49] investigated the effect of concentration of $\mathrm{Al}_{2} \mathrm{O}_{3}$ nanofluid on 6 turn copper PHP (i.d $1.45 \mathrm{~mm}, 0 . \mathrm{d} 2.45 \mathrm{~mm}$ ) by varying the concentration from $0.25 \%$ to $2.5 \%$ (fig. 7 ) at a filling ratio of $50 \%$. It was found that a minimum resistance is obtained at $1.0 \%$ concentration. At an input power of $50 \mathrm{~W}$, the resistance of PHP decreased from 1.112 for DI water to $0.8045^{\circ} \mathrm{C} / \mathrm{W}$ for $1.0 \%$ of nanofluidat the heat load of $40 \mathrm{~W}$. As the concentration of nanofluid further increased from $1.25 \%$ to $2.5 \%$, a reverse effect was obtained. Similar result was obtained by Lin et al.[24] for silver nanofluid ;Qu et al.[11] for alumina nanofluid, etc. As the concentration of the nanofluid increases, the heat conduction coefficient also increases. But in comparison to $1.25 \%, 1 \%$ concentration fluid gave better results. This is because of the fact that higher concentration makes the higher viscosity which makes the bubble difficult to produce and the force of friction causes obstruction of the liquid slug with tube wall becomes larger, so obstruction is relatively greater when the bubble is promoted and influences the whole efficiency of the heat transfer.

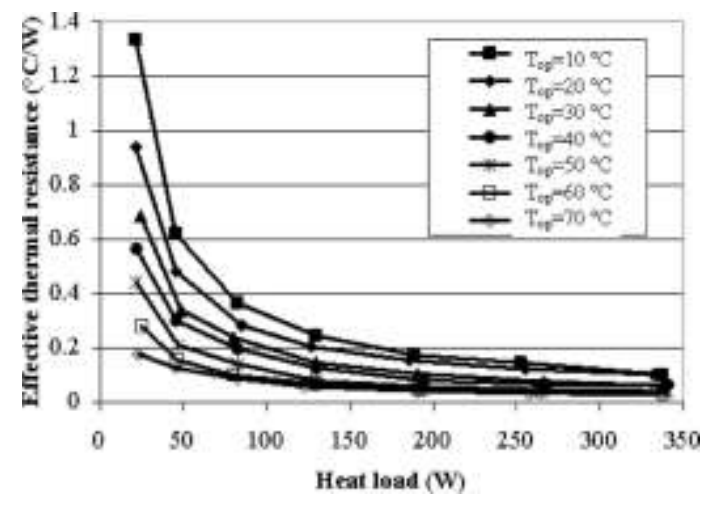

Fig 3Thermal resistance at various heat loads and operating temperatures[20]

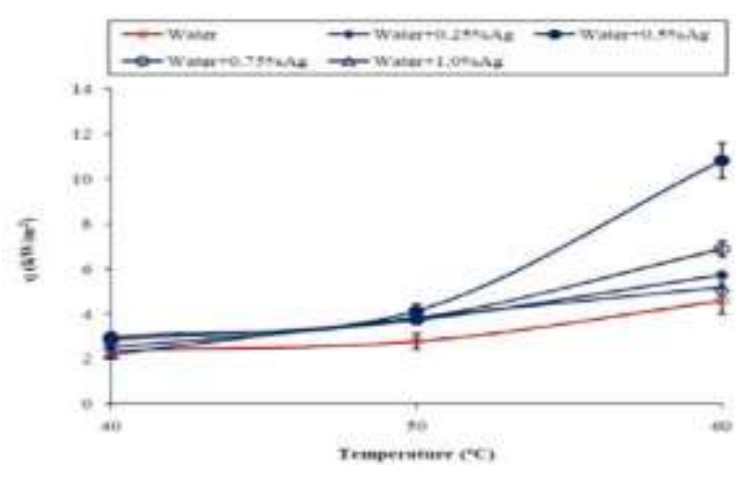

Fig 4 The operating temperature effect on the heat transfer rate of CLOHP/CV at an aspect ratio of 25 [25]. 

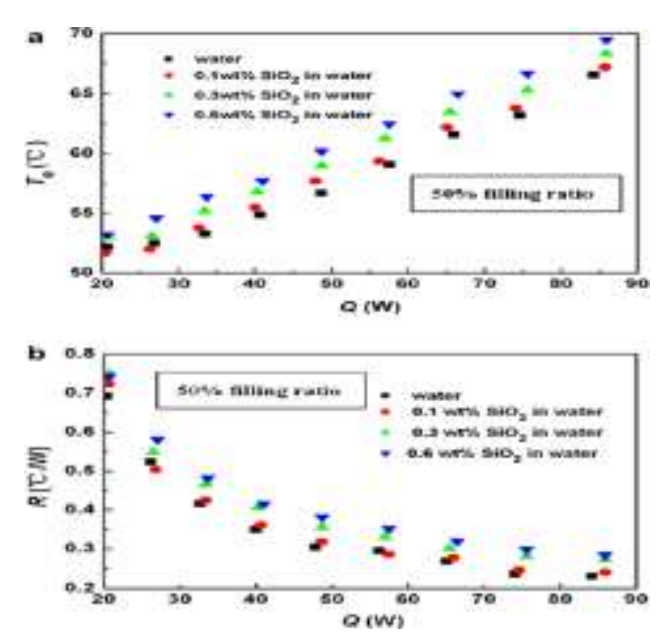

Fig. 5 Thermal performance of the PHP/OHP charged with $\mathrm{SiO}_{2} /$ water nanofluids at different mass concentration(a) Average evaporator temperature; (b) overall thermal resistance[26].
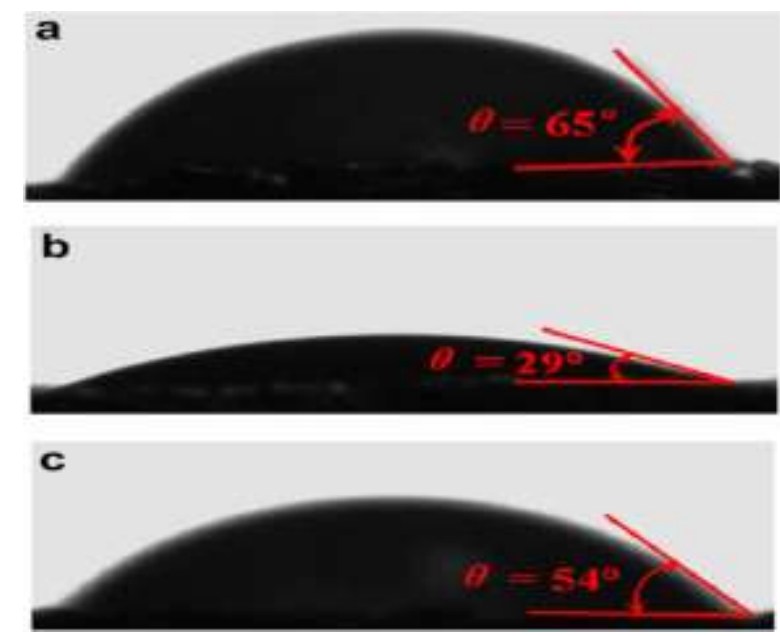

Fig 6Static contact angles of droplet on different surfaces: (a) pure water droplet on clean surface boiled in pure water, $\theta$ $=65^{\circ}$; (b) $\mathrm{SiO}_{2} /$ water nanofluid droplet on silica nanoparticles-deposited surface at the evaporator, $\theta=29^{\circ}$; and (c) $\mathrm{Al}_{2} \mathrm{O}_{3}$ /water nanofluid droplet on alumina nanoparticlesdeposited surface at the evaporator, $\theta=54^{0}[26]$.

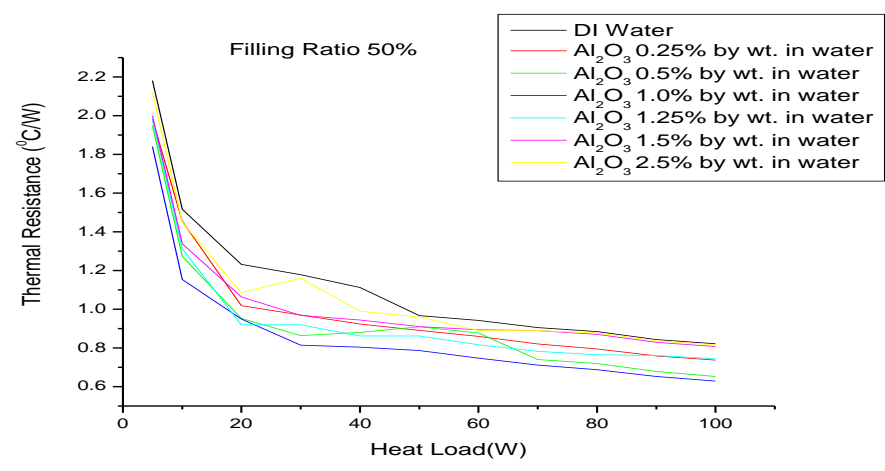

Fig 7 Effect of concentration of $\mathrm{Al}_{2} \mathrm{O}_{3}$ on thermal resistance of PHP at FR $50 \%\lceil 491$

VI. Conclusions \& Future Scope

From the above discussion it can be said that nanofluids are potential fluids to be used as working fluid in PHP/OHP because of the following reasons:

1. Presence of nano particles can affect the startup temperature of the PHP. However, the startup temperature depends on the particle size.

2. When the nanoparticle size is reduced, the thermal conductivity of the nanofluid increases. However, the nanoparticles may agglomerate, settle, or coalesce to the walls with long-term operation of the nanofluid PHP. Preliminary long-term testing of the prototype device showed that the heat transfer performance remained the same over a period of at least six months.

3. Lower operating temperatures and greater pulsations of amplitudes can be obtained with the use of nanofluids in PHP.

4. Enhanced nucleation sites and reduced bubble diameter can be obtained.

5. The surface wettability or the contact angle of the nanoparticles with the surface plays an important role in selection of the nanofluid.

6. Among the four shapes(cylinder, blade, plate and brick) studied so far, the cylindrical shape gives the best result.

\section{Acknowledgement}

Authors are grateful to AICTE,ND for sanctioning a research project to one of them (B hawnaVerma) 
Nano fluid-An alternative fluid in Pulsating Heat Pipe/Oscillating Heat Pipe

Table: Work done on PHP/OHP with nanofluid as the working fluid

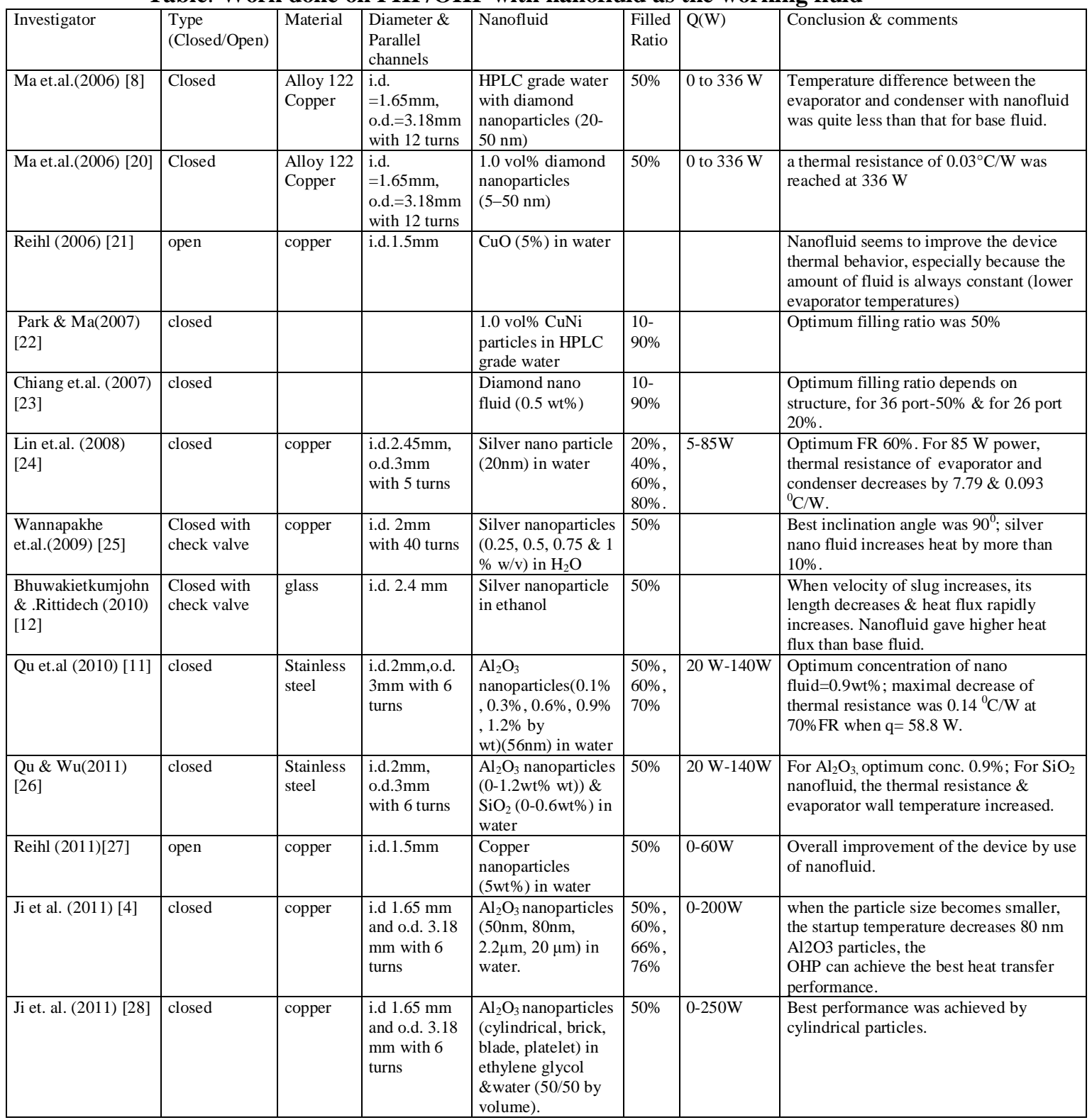

\section{References}

[1] H.B.Ma, M.A.Hanlon, CL. Chen, An investigation of oscillating motions in a miniature pulsating heat pipe, Microfluidics and Nanofluidics, 2(2),2005, 171-179.

[2] Akachi H., Polášek F. and Štulc P., Pulsating Heat Pipes, Proc. 5th Int. Heat Pipe Symp., Melbourne, 1996, $208-217$.

[3] Sameer Khandekar, Manfred Groll, P.Charoensawan, S. Rittidech, P.Terdtoon, Closed and open loop Pulsating Heat pipes, Proc 13th International Heat Pipe Conference, Shanghai, China, September 21-25, 2004.

[4] YulongJi, HongbinMaa, Fengmin Su, Guoyou Wang, Particle size effect on heat transfer performance in an oscillating heat pipe, Experimental Thermal and Fluid Science 35 ,2011, 724-727.

[5] Sarit Kumar Das , Stephen U. S. Choi \&Hrishikesh E. Patel , Heat Transfer in Nanofluids-A Review, Heat Transfer Engineering, 27(10), 2006, 3-19.

[6] Y. Xuan and Q.Li, Heat Transfer enhancement of nanofluids, International Journal of Heat and fluid Flow, 21,2000,58-64.

[7] D. Wen, Y. Ding, Effect of particle migration on heat transfer in suspensions of nanoparticles flowing through minichannels, Microfluidic. Nanofluidic.1,2005,183-189.

[8] H.B.Ma, C.Wilson, B. Borgmeyer, K.Park and Q.Yu, Effect of nanofluid on the heat transport capability in an oscillating heat pipe, Applied Physics letters 88,2006,143116 1-3.

[9] S.W.Kang, W.C.Wei, S.H.Tsai, C.C.Huang, Experimental investigation of Nanofluids on sintered heat pipe thermal performance, Applied Thermal Engineering 29 ,2009, 973-979.

[10] Guo-Shan Wang, Bin Song, Zhen-Hua Liu, Operation characteristics of cylindrical miniature grooved heat pipe using aqueous CuONanofluids, Experimental Thermal and Fluid Science 34,2010, 1415-1421.

[11] JianQu, Hui-ying Wu, Ping Cheng, Thermal performance of an oscillating heat pipe with Al2O3-water Nanofluids, International communications in Heat and Mass Transfer 37,2010, 111-115.

[12] N.Bhuwakietkumjohn\&S.Rittidech, Internal flow patterns on heat transfer characteristics of a closed-loop oscillating heat pipe with check valves using ethanol and a silver nano ethanol mixture, Experimental Thermal and Fluid Sciences, 34, 2010, 10001007 . 
[13] Sameer Khandekar, Manfred Groll, An insight into thermo-hydrodynamic coupling in closed loop pulsating heat pipes, International Journal of Thermal Sciences 43,2004, 13-20.

[14] Karimi G. and Culham J.R., Review and assessment of Pulsating Heat Pipe mechanism for high heat flux electronic cooling,Proc. of Ninth Intersociety Conf., Thermal and Thermomechanical Phenomena in electronic systems, ITHERM'04, Vol 2 (2004), 52-59.

[15] S.Khandekar, Thermo-hydrodynamics of closed loop pulsating heat pipe, doctrol Thesis, Univ of Stuttgart, Germany, 2004.

[16] Yuwen Zhang, A. Faghri, Advances and Unsolved Issues in Pulsating Heat Pipes, Heat Transfer Engineering 29(1), $2008,20-44$.

[17] R.Savino, R.D. Paola, A. Cecera, R. Fortezza, Self-rewetting heat transfer fluids and nanobrines for space heat pipe, ActaAstronautica 67,2010, 1030-1037.

[18] Zhao, C. Y., and Lu, T. J., Analysis of Microchannel Heat Sinks for Electronics Cooling, International Journal of Heat and Mass Transfer,. 45(24),2002, 4857-4869.

[19] VisineeTrisaksri and SomchaiWongwises, Critical review of heat transfer characteristics of Nanofluids, www.123seminarsonly.com

[20] H.B.Ma, C.Wilson, K.Park ,Q.Yu, S.U.S. Choi, M.Tirumala, An An Experimental Investigation of Heat Transport Capability in a Nanofluid Oscillating Heat Pipe, Journal of Heat Transfer 128,2006,1213-1216.

[21] Riehl, R. R., "Overview on the Loop Heat Pipe and Pulsating Heat Pipe Development using alternative Working Fluid and Nanofluid" http://www2.dem.inpe.br/rriehl/Riehl-two-phase.pdf, International Two-Phase Thermal Control Workshop NASA/ESA, USA, September 19-21, 2006.

[22] K. Park, H.B. Ma, Nano-fluid effect on heat transport capability in a well-balanced oscillating heat pipe, Journal of Thermophysics and Heat Transfer 21 (2),2007, 443-445.

[23] Yi Wai Chiang, Masahiro Kawaji, Christian Lu, Experimental investigation of unlooped pulsating heat pipe (PHP) performance, in: Preprint of the 14th International Heat Pipe Conference, 2007, Session 09.

[24] Yu-Hsing Lin, Shung-Wen Kang, Hui-Lun Chen, Effect of silver nano-fluid on pulsating heat pipe thermal performance, Applied Thermal Engineering 28,2008, 1312-1317.

[25] S. Wannapakhe, S. Rittidech1, B. Bubphachot and O. Watanabe, Heat transfer rate of a closed-loop oscillating heat pipe with check valves using silver nanofluid as working fluid, Journal of Mechanical Science and Technology 23,2009, 1576-1582.

[26] JianQu, Hui-ying Wu, Thermal performance of oscillating heat pipe with SiO2-water and Al2O3-water Nanofluids, International Journal of Thermal Sciences, 50,2011, 1954-1962.

[27] R.R.Riehl, N.D. Santos, Water-copper nanofluid application in an open loop pulsating heat pipe, Applied Thermal Engineering, XXX,2011, 1-5.

[28] Y. Ji, C. Wilson, H. Chen, H.Ma, Particle shape effect on heat transfer performance in an oscillating heat pipe, Nanoscale Research Letters (6) ,2011, 296.

[29] H.E. Patel, T. Sundararajan, T. Pradeep, A. Dasgupta, N. Dasgupta, S.K. Das, A micro-convection model for thermal conductivity of nanofluids, PRAMANA J-Phys. 65,2005, 863-869.

[30] Das, S. K., Putra, N., Thiesen, P., and Roetzel, W., Temperature Dependence of Thermal Conductivity Enhancement for Nanofluids, Transactions of ASME, Journal of Heat Transfer, 125,2003, 567-574.

[31] C.J. Yu, A.G. Richter, A. Datta, M.K. Durbin, P. Dutta, Molecular layering in a liquid on a solid substrate: an X-ray reflectivity study, Physica B 283,2000, 27-31.

[32] P. Keblinski, S.R. Phillpot, S.U.S. Choi, J.A. Eastman, Mechanisms of heat flow in suspensions of nano-sized particles (nanofluids),Int. J. Heat Mass Transfer $45,2002,855-863$.

[33] C.Y. Tsai, H.T. Chien, P.P. Ding, B. Chan, T.Y. Luh, P.H. Chen, Effect of structural character of gold nanoparticles in nanofluid on heat pipe thermal performance, Materials Letters 58, 2004, 1461- 1465.

[34] S.W. Kang, W.C. Wei, S.H. Tsai, S.Y. Yang, Experimental investigation of silver nano-fluid on heat pipe thermal performance, Applied Thermal Engineering, 26,2006, 2377-2382.

[35] Zhen-Hua Liu, Yuan-Yang Li, Ran Bao, Compositive effect of nanoparticle parameter on thermal performance of cylindrical micro-grooved heat pipe using Nanofluids,International Journal of Thermal sciences, 50,2011, 558-568.

[36] Maryam Shafahi, Vincenzo Bianco , KambizVafai a, OronzioManca ,Thermal performance of flat-shaped heat pipes using nanofluids , International Journal of Heat and Mass Transfer 53,2010, 1438-1445.

[37] Maryam Shafahi, Vincenzo Bianco, KambizVafai, OronzioManca,An investigation of the thermal performance of cylindrical heat pipes using nanofluids, International Journal of Heat and Mass Transfer 53,2010, 376-383

[38] P. Naphon, P.Assadamongkol, T.Borirak, Experimental investigation of titanium Nanofluids on the heat pipe thermal efficiency, International Communications in Heat and Mass Transfer 35,2008, 1316-1319.

[39] P.Naphon, d. Thongkum, P. Assadamongkol, Heat pipe efficiency enhancement with refrigerant-nanoparticles mixtures, Energy Conservation management 50,2009, 772-776.

[40] Riehl, R. R., “Analysis of loop heat pipe behavior using nanofluid”Heat Powered Cycles International Conference (HPC), New Castle, UK, paper 06102, Sept 11-14, 2006

[41] S. Wang, Z. Lin, W. Zhang \& J. Chen, Experimental study on pulsating heat pipe with functional thermal fluids, International Journal of Heat and Mass Transfer52,2009, 5276-5279.

[42] S. Maezawa, KY. Gi., A. Minamisawa and H. Akachi H, Thermal Performance of Capillary Tube Thermosyphon, Proc. of the ninth international heat-pipe conference, USA (1996) 791-795

[43] J. Eapen, W.C. Williams, J. Buongiorno, L. Hu, S. Yip, Mean-field versus microconvection effects in nanofluid thermal conduction, Phys. Rev. Lett. 99,2007, 095901.

[44] C.J.Yu and A.G.Richter, A.Datta, M.K.Durbin, P.Dutta, Molecular laywering in a liquid on a solid substrate: an X-ray reflectivity study, Physica B 283,2000, 27-31.

[45] P. Keblinski, S.R. Phillpot, S.U.S. Choi, J.A. Eastman, Mechanisms of heat flow in suspensions of nano-sized particles (nanofluids), Int. J. Heat Mass Transfer 45,2002, 855-863.

[46] B.B.Mikic, W.M.Rohsenow, A new correlation of pool boiling data including the effect of heating surface characteristics, Journal of heat Transfer $91,1969,245-250$.

[47] C.H. Wang, V.K. Dhir, Effect of surface wettability on active nucleation site density during pool boiling of water on a vertical surface, J. Heat Transfer $115,1993,659-669$

[48] W. Qu , H.B.Ma, Theoretical startup of a pulsating heat pipe, International Journal of Heat and Mass Transfer, 50 (11-12),2007, 2309-2316.

[49] Verma, B., Yadav, V.L. and Srivastava, K.K., Experimental study on startup of pulsating heat pipe with $\mathrm{Al}_{2} \mathrm{O}_{3}$ nano fluid (Communicated). 